TITLE:

\title{
Seed dormancy and germination traits of an endangered aquatic plant species, Euryale ferox Salisb. (Nymphaeaceae)
}

$\operatorname{AUTHOR}(S)$ :

Imanishi, Ayumi; Imanishi, Junichi

CITATION:

Imanishi, Ayumi ... [et al]. Seed dormancy and germination traits of an endangered aquatic plant species, Euryale ferox Salisb. (Nymphaeaceae). Aquatic Botany 2014, 119: 80-83

ISSUE DATE:

2014-10

URL:

http://hdl.handle.net/2433/191026

RIGHT:

C 2014 Elsevier B.V.; この論文は出版社版でありません。引用の際には 出版社版をご確認ご利用ください。; This is not the published version. Please cite only the published version. 
1 Seed dormancy and germination traits of an endangered aquatic plant species, Euryale ferox

2 Salisb. (Nymphaeaceae)

3

$4 \quad$ Ayumi Imanishi ${ }^{\mathrm{a}}$ and Junichi Imanishi ${ }^{\mathrm{b}}$

5

$6 \quad{ }^{a}$ Faculty of Applied Sociology, Kinki University, 228-3 Shinkamikosaka, Higashiosaka, Osaka

$7 \quad$ 577-0813, Japan

$8{ }^{\mathrm{b}}$ Graduate School of Global Environmental Studies, Kyoto University, Oiwake-cho, Kitashirakawa,

9 Sakyo-ku, Kyoto 606-8502, Japan

11 E-mail addresses: AI, ayumi.imanishi@a.email.ne.jp; JI, imanishi.junichi.6c@kyoto-u.ac.jp

13 Corresponding author: Ayumi Imanishi

14 Phone number: $+81-6-4307-4168$

\section{ABSTRACT}

17 Populations of Euryale ferox Salisb. have declined throughout its global range because of habitat

18 loss and degradation. The present study aimed to evaluate the influence of storage temperature (4 
1 and $\left.20^{\circ} \mathrm{C}\right)$, storage period $(0,90,180,270$, and 360 days), light condition (light and darkness),

2 germination temperature (constant $10,15,20,25$, and $30^{\circ} \mathrm{C}$ ), and seed size (two classes from $0.5 \mathrm{~cm}$

3 to less than $1.2 \mathrm{~cm}$, and from $1.2 \mathrm{~cm}$ to less than $1.6 \mathrm{~cm}$ ) on germination of E. ferox seeds. Our

4 results indicated that seeds were dormant when shed and $4{ }^{\circ} \mathrm{C}$ stratification promoted germination

5 more effectively than $20^{\circ} \mathrm{C}$. After stratification at $4{ }^{\circ} \mathrm{C}$, the germination frequency of the larger

6 seeds peaked at 90 days' stratification, whereas the smaller seeds maintained high germination

7 frequencies up to 180 days' stratification. The different germination responses between smaller and

8 larger seeds may reflect a difference in the rate of induction of dormancy in the annual dormancy

9 cycle. Seeds germinated in both light and darkness, which demonstrated that light is not involved in

10 the regulation of E. ferox seed germination. The optimal temperature for germination was $25^{\circ} \mathrm{C}$.

11 Light condition $\times$ germination temperature interaction caused significantly higher germination frequency at $30{ }^{\circ} \mathrm{C}$ in light than in darkness, and the opposite trend at $15^{\circ} \mathrm{C}$.

Keywords: Nymphaeaceae, vulnerable, cold stratification, induction of dormancy, interaction of light 
1

2

3

4

5

6

7

8

9

\section{Introduction}

Euryale ferox Salisb. (Nymphaeaceae) is a prickly annual aquatic herb with gigantic floating

leaves $0.3-1.5 \mathrm{~m}$ in diameter. It is distributed from northwestern India to Japan and inhabits meso-

and eutrophic water bodies such as lakes, ponds, reservoirs and rivers. In Japan, the species'

distribution ranges from Kyushu to the northern part of Honshu, but habitat loss caused by drainage

or land reclamation and water pollution has led to population decline and the species is classified as

"vulnerable" in the Red List of Threatened Plants of Japan (Ministry of the Environment of Japan,

2012). Moreover, its populations have declined throughout its global range (Schneider et al., 2003).

It is well known that natural populations of $E$. ferox are subject to considerable annual variation

in number of individuals (Miyashita, 1983; Kume, 1987). The species' seeds are believed capable of

remaining dormant, even over several decades, when the external environment is unsuitable for

germination (Wakita, 1959; Kadono, 1983; Ohtaki, 1987). This trait may influence annual variation

in population sizes. However, seed dormancy and the germination characteristics of this species are

poorly understood.

Seed dormancy is an adaptive mechanism to ensure that germination takes place in a suitable

location and in suitable conditions (e.g., Baskin and Baskin, 2001; Fenner and Thompson, 2005).

Temperature is regarded as the most important factor influencing seed dormancy (Bouwmeerster and 
1 Karssen, 1992, 1993). Kumaki and Minami (1973) reported that about 30\% of E. ferox seeds

2 germinated after prechilling at $2-3{ }^{\circ} \mathrm{C}$ for 1 month, whereas at constant room temperature no seeds

3 germinated. This result indicated that cold stratification breaks dormancy of the seeds. However,

4 since the optimum period of stratification varies among species (Baskin and Baskin, 2001), and thus

5 it is necessary to determine the optimal period of cold stratification for maximum germination and

6 the influence of extended seed preservation on germination.

7 shorter after-ripening period than large seeds has been observed (Okada 1935; Wakita 1959).

After release of seed dormancy, environmental factors such as temperature and light promote germination (Benvenuti et al., 2001; Penfield et al., 2005; Jha et al., 2010). A systematic quantitative study has not been conducted on the effect of temperature and light on germination of $E$. ferox seeds, but from field observations it is estimated that the seeds germinate between 20 and $25{ }^{\circ} \mathrm{C}$ and do not require light for germination (Okada, 1935; Wakita, 1959).

In addition to temperature and light, seed size may play an important role in seed germination for some species (Cideciyan and Malloch, 1982; Zammit and Zedler, 1990; Leverett and Jolls, 2013).

Seeds of $E$. ferox are about $1 \mathrm{~cm}$ in diameter and their size varies among populations (Okada, 1928; Miyashita, 1983), among individuals in a population (Miyashita 1983; Hashimoto 1986), and even within the same individual (Hagiwara 1993). The phenomenon that small seeds of $E$. ferox require a However, a quantitative study of the relationship between seed size and germination has not been 
1

2

November 2009 in the Hiranosawa pond, Kameoka, western Japan $\left(35^{\circ} 04^{\prime} 03^{\prime \prime}\right.$ N, 135 $33^{\prime} 55^{\prime \prime}$ E).

conducted.

The aim of the present research was to quantitatively verify seed dormancy and germination traits of E. ferox focusing on the influence of seed storage period, storage temperature, light condition, germination temperature, and seed size.

\section{Materials and methods}

\subsection{Seed collection and storage}

Fresh fruits and floating fresh seeds with arils were collected from late October to early

11 Hiranosawa pond consists of three small ponds with a total area of about $10 \mathrm{ha}$. It has been used as an agricultural reservoir. Genetic diversity of $E$. ferox is low within and among populations in Japan and the genotype of $E$. ferox in the Hiranosawa pond is the most widely distributed one in western Japan (the authors' unpublished data). Thus we considered that our samples are representative of the genetic diversity in this region. Seeds were separated from the fruits and the arils were removed in the laboratory. Small green- or skin-colored immature seeds were excluded. 
$1 \quad 1.2 \mathrm{~cm}$ to less than $1.4 \mathrm{~cm}$; from $1.4 \mathrm{~cm}$ to less than $1.6 \mathrm{~cm}$; and greater than $1.6 \mathrm{~cm}$. The number of

2 seeds in each size group was about 1,800 seeds, about 6,500 seeds, about 4,400 seeds, about 1,000

3 seeds, and 19 seeds, respectively. in aluminum foil in order to avoid seed deterioration caused by fungal infection. The containers were filled with water and placed at either a constant low temperature $\left(4{ }^{\circ} \mathrm{C}\right)$ to simulate the winter water temperature or a constant warm temperature $\left(20^{\circ} \mathrm{C}\right)$ to simulate the early summer water temperature in a small pond (Shimomura et al., 2010). Water was replaced regularly in complete darkness under a green safelight.

\subsection{Germination tests}

Germination tests were performed in light and darkness at constant temperatures of 10, 15, 20,

30 seeds each were placed in plastic containers and the seeds were submerged with water. The of the number of collected seeds in each size group, four (from $0.5 \mathrm{~cm}$ to less than $1.0 \mathrm{~cm}$ ), 14 (from

$171.0 \mathrm{~cm}$ to less than $1.2 \mathrm{~cm}$ ), 10 (from $1.2 \mathrm{~cm}$ to less than $1.4 \mathrm{~cm}$ ) and two seeds (from $1.4 \mathrm{~cm}$ to less than $1.6 \mathrm{~cm}$ ) per container were sown, respectively. Seeds of greater than $1.6 \mathrm{~cm}$ diameter were not 
1 used in germination tests because of the limited number of seeds available. We defined seeds from

$2 \quad 0.5$ to less than $1.2 \mathrm{~cm}$ diameter as small seeds and those from 1.2 to less than $1.6 \mathrm{~cm}$ diameter as

3 large seeds.

4

In the light treatments, seeds were exposed to warm white fluorescent light providing

5 photosynthetically active radiation of $20 \mu \mathrm{mol} \mathrm{m}^{-2} \mathrm{~s}^{-1}$ for $12 \mathrm{~h} \mathrm{day}^{-1}$. For the darkness treatments, all

6 handling of containers was conducted in complete darkness under a green safelight and the

7 containers were wrapped with aluminum foil after seeding.

For the light treatments, germination counts were made at intervals of 2-3 days for 60 days. For

9 the darkness treatments, the containers were unwrapped at the end of the germination period (60

days), and the number of germinated seeds was counted. Seeds were recorded as germinated when

11 the protruding radicle was $\geq 1 \mathrm{~mm}$ in length as defined by Okada (1935).

\subsection{Data analysis}

To examine the effects of light condition, germination temperature, and seed size on

germination, we analyzed germination of seeds stratified at $4{ }^{\circ} \mathrm{C}$ for 90 days by constructing a

generalized linear model with a binomial distribution with number of germinated seeds as the 
1 temperature excluding $10{ }^{\circ} \mathrm{C}$, light condition $\times$ seed size, and germination temperature excluding

$2 \quad 10{ }^{\circ} \mathrm{C} \times$ seed size), and one interaction of the three factors (light condition $\times$ germination

3 temperature excluding $10{ }^{\circ} \mathrm{C} \times$ seed size) as explanation variables. We adopted the best model by

4 stepwise selection. For the statistical analysis, we used the glm and stepAIC functions in R ver. 3.1.0

5 (R Core Team, 2014) and set the significance level as $p<0.05$.

6

7 3. Results

8

Few seeds germinated immediately after harvest (no stratification) (Fig. 1). Regarding the seeds

stratified at $4{ }^{\circ} \mathrm{C}$, small seeds maintained high germination frequencies until at least 180 days (Fig.

11 1A and B). The germination frequency of large seeds was highest at 90 days and decreased at 180

days regardless of light condition (Fig. 1C and D).

With regard to the seeds stratified at $4{ }^{\circ} \mathrm{C}$ that germinated in light, the median germination time

14 (i.e., the number of days until at least 50\% germination frequency was attained in all of the four

replicates within 60 days) was evaluated for the seven cases listed in Table 1. The shortest median

germination time was $5.5 \pm 0.5$ days (mean $\pm \mathrm{SD}$ ) for small seeds stratified for 180 days and 
$10,0,1.7 \pm 1.9,28.3 \pm 7.9$, and $29.2 \pm 10.7 \%$ (mean $\pm \mathrm{SD}$ ) at $10,15,20,25$, and $30^{\circ} \mathrm{C}$, respectively,

2 and in darkness were $0,0,12.5 \pm 7.4,47.5 \pm 18.9$, and $18.3 \pm 8.8 \%$ at $10,15,20,25$, and $30^{\circ} \mathrm{C}$,

3 respectively. After 180,270 or 360 days of stratification at $20^{\circ} \mathrm{C}$, few or no seeds germinated.

\section{Discussion}

17 for several months can break the dormancy (Fig. 1). Dormancy release was possible with 4 and 
1 stratified at $4{ }^{\circ} \mathrm{C}$, the germination frequency of large seeds peaked at 90 days (Fig. 1C and D),

2 whereas small seeds maintained high germination frequencies until at least 180 days (Fig. 1A and B).

3 It was hypothesized that non-germinated seeds did not lose viability but dormancy was re-induced

4 because the embryos were white and hard when dissected after completion of the germination tests,

5 although the induction of dormancy was not investigated. The different germination responses

6 between small and large seeds may reflect a difference in the rate of induction of dormancy in annual

7 dormancy cycle.

Most flowers of E. ferox are cleistogamous, but chasmogamous flowers are also produced

9 (Okada and Otaya, 1930). In many species, germination responses differ between seeds from

cleistogamous and chasmogamous flowers (e.g. Weiss, 1980; Trapp and Hendrix, 1988; Ferreira and

flowers are slightly larger than those from cleistogamous flowers because fruits from chasmogamous

flowers contain significantly fewer seeds than cleistogamous flowers and seed size is inversely

correlated to the total number of seeds in each fruit. Although more research is required, it is

hypothesized that $E$. ferox may produce many small seeds, in which the rate of induction of 
1

2

unimportant for regulation of germination in this species. It is believed that $E$. ferox can form a

persistent seed bank (Wakita, 1959; Kadono, 1983; Otaki, 1987). A light requirement for germination is a common feature among species that form persistent seed banks (Pons 2000). However,

germination in large-seeded species might be expected to be insensitive to light because seedlings

from large seeds can emerge successfully from a much greater depth that light cannot penetrate

(Pons, 2000; Milberg et al., 2000; Pearson et al., 2002; Fenner and Thompson, 2005). Seeds of E.

ferox are large (about $1 \mathrm{~cm}$ in diameter), which may be a factor in their not requiring light for

germination.

The present study quantitatively verified that the optimal temperature for germination was $25{ }^{\circ} \mathrm{C}$ because the median germination times at $25^{\circ} \mathrm{C}$ were shorter than those at $20^{\circ} \mathrm{C}$ (Table 1 ), and the germination frequency was high at both 20 and $25^{\circ} \mathrm{C}$ (Fig. 1). In some species, light interacts with temperature to regulate seed germination (Baskin and Baskin, 2001). In the present study, the generalized linear model focusing on $4{ }^{\circ} \mathrm{C}$ stratification of 90 days revealed that light condition $\times$ germination temperature interaction significantly affected germination (Table 2). The significant interaction was due to higher germination frequencies at $30^{\circ} \mathrm{C}$ in light than darkness and higher germination frequencies at $15{ }^{\circ} \mathrm{C}$ in darkness than in light. The interaction between light and temperature is considered to be beneficial for germination of E. ferox, as the seeds often sink to the bottom of water bodies. If the temperature around the seed is low even though light reaches the 
1 bottom of the water body, germination will be inhibited, which enables avoidance of an unsuitable

2 external environment for growth. On the other hand, germination could occur at a low temperature

3 when the seeds are buried at the bottom of a water body and do not receive light, which permits

4 increased opportunity for germination close to the level that would be observed if the seeds were not

5 covered by soil. 
1 Acknowledgments: We are grateful to Mr. Ryuzo Hayashi in Kameoka city for collecting seeds.

2 This work was supported in part by the Osaka University Program for the Support of Networking

3 among Present and Future Researchers. 
1

\section{References}

2

Baskin, C.C., Baskin, J.M., 2001. Seeds: Ecology, Biogeography, and Evolution of Dormancy and Germination. Academic Press, San Diego.

Benvenuti, S., Macchia, M., Miele, S., 2001. Light, temperature and burial depth effects on Rumex obtusifolius seed germination and emergence. Weed Res. 41, 177-186.

Bouwmeester, H.J., Karssen, C.M., 1992. The dual role of temperature in the regulation of the seasonal changes in dormancy and germination of seeds of Polygonum persicaria L. Oecologia 90, 88-94.

Bouwmeester, H.J, Karssen, C.M., 1993. Annual changes in dormancy and germination in seeds of Sisymbrium officinale (L.) Scop. New Phytol. 124, 179-191.

Cideciyan, M.A., Malloch, A.J.C., 1982. Effects of seed size on the germination, growth and competitive ability of Rumex crispus and Rumex obtusifolius. Jour. Ecol. 70, 227-232.

Fenner, M., Thompson, K., 2005. The Ecology of Seeds. Cambridge University Press, Cambridge.

Ferreira, M.I., Reinhardt, C.F., 1999. The role of temperature in the germination of subterranean and aerial seeds of Commelina benghalensis L. S. Afr. J. Plant Soil 16, 165-168.

Hagiwara, T., 1993. Euryale ferox Salisb. Bull. Water Plant Soc., Jpn 51, 32-34 (in Japanese).

Hashimoto, T., 1986. Euryale ferox Salisb. of Chizuka-pond in Fukuyama city. Bull. Water Plant 
1

Soc., Jpn 26, 6-11 (in Japanese).

Jha, P., Norsworthy, J.K., Riley, M.B., Bridges Jr, W., 2010. Annual changes in temperature and light requirements for germination of Palmer amaranth (Amaranthus palmeri) seeds retrieved from soil. Weed Sci. 58, 426-432.

Kadono, Y., 1983. Natural history of Euryale ferox Salisb. Nat. Stud. 29, $63-66$ (in Japanese).

Kadono, Y., Schneider, E.L., 1987. The life history of Euryale ferox Salisb. in south-western Japan with special reference to reproductive ecology. Plant Sp. Biol. 2, 109-115.

Kumaki, Y., Minami, Y., 1973. Seed germination of “Onibasu” Euryale ferox Salisb. (II). Bull. Fac. Educ., Kanazawa Univ., Nat. Sci. 22, 71-78.

Kume, O., 1987. Growth situation of Euryale ferox Salisb. in Kagawa prefecture I. Bull.Water Plant Soc., Jpn 27, 16-19 (in Japanese).

Leverett, L.D., Jolls, C.L., 2013. Cryptic seed heteromorphism in Packera tomentosa (Asteraceae): differences in mass and germination. Plant Spec. Biol.. doi: 10.1111/1442-1984.12011

Maeda, O., Nakamichi, T., Takahashi, G., 1983. Euryale ferox Salisb. in Shishitsuka-Oike. Tsukuba no kankyo kenkyu 7, 80-85 (in Japanese).

Milberg, P., Andersson, L., Thompson, K., 2000. Large-seeded species are less dependent on light for germination than small-seeded ones. Seed Sci. Res. 10, 99-104.

Ministry of the Environment of Japan, 2012. Red List of Threatened Plants of Japan, 
1

2 Miyashita, Y., 1983. Euryale ferox Salisb. of Sakata lagoon in Niigata prefecture. Bull. Water Plant http://www.biodic.go.jp/english/rdb/rdb_f.html [accessed 22 July 2013]. Soc., Jpn 11, 4-6 (in Japanese).

4

Otaki, S., 1987. Euryale ferox Salisb. in Japan. Nihon no seibutsu 1(4), 48-55. (in Japanese)

5

Okada, Y., 1928. Study of Euryale ferox Salisb. I. On the size of leaves, fruits, etc., with some

6 remarks on the mode of expansion of the leaf blade. Sci. Rep. Tohoku Imp. Univ., Ser. 4, 3,

7 $271-278$

8

Okada, Y., 1935. Long-term dormancy of Euryale ferox Salisb. seeds. Seitaigakuteki kenkyu 1, 14-22 (in Japanese).

Okada, Y., Otaya, T., 1930. Study of Euryale ferox Salisb. VI. Cleistogamous versus chasmogamous flowers. Bot. Mag. (Tokyo) 44, 369-373.

Pearson, T.R.H., Burslem, D.F.R.P., Mullins, C.E., Dalling, J.W., 2002. Germination ecology of neotropical pioneers: interacting effects of environmental conditions and seed size. Ecology 83, 2798-2807.

Penfield, S., Josse, E.-M., Kannangara, R., Gilday, A.D., Halliday, K.J., Graham, I.A., 2005. Cold and light control seed germination through the bHLH transcription factor SPATULA. Curr. Biol. $15,1998-2006$. 
1

2 R Core Team, 2014. R: A language and environment for statistical computing. R Foundation for abramsii. Oecologia 84, 24-28.

in Plant Communities (2nd edition). CAB International, Wallingford, pp. 237-260. Statistical Computing, Vienna, Austria. URL http://www.R-project.org/.

Schneider, E.L., Tucker, S.C., Williamson, P.S., 2003. Floral development in the Nymphaeales. Int. J. Plant Sci. 164, S279-S292.

Shimomura, H., Kamakura, T., Masuda, H., 2010. Seasonal variations of water quality and the sediment quality of Benten pond in Joetsu University of Education: as one of the basic data to utilize a small reservoir for an environmental education. Bull. Joetsu Univ. Educ. 29, 249-255 (in Japanese with English abstract).

Trapp, E.J., Hendrix, S.D., 1988. Consequences of a mixed reproductive system in the hog peanut, Amphicarpaea bracteata, (Fabaceae). Oecologia 75, 285-290.

Wakita, H., 1959. Study on the fresh water plants in Nagoya and north-eastern part of Owari province; including ecological study of Euryale ferox Salisbury. Chubu nihon shizen kagaku chosadan hokoku 3, 5-7 (in Japanese).

Weiss, P.W., 1980. Germination, reproduction and interference in the amphicarpic annual Emex spinosa (L.) Campd. Oecologia 45, 244-251.

Zammit, C., Zedler, P., 1990. Seed yield, seed size and germination behavior in the annual Pogogyne 


\section{Figure captions}

2

3 Fig. 1. Germination frequency of $E$. ferox seeds stratified at $4{ }^{\circ} \mathrm{C}$ and germinated at five constant temperatures ranging from 10 to $30^{\circ} \mathrm{C}$. (A) Small seeds germinated in light, (B) small seeds germinated in darkness, (C) large seeds germinated in light, and (D) large seeds germinated in

6 darkness. Symbols and error bars represent the mean $\pm \operatorname{SD}(n=4)$. 


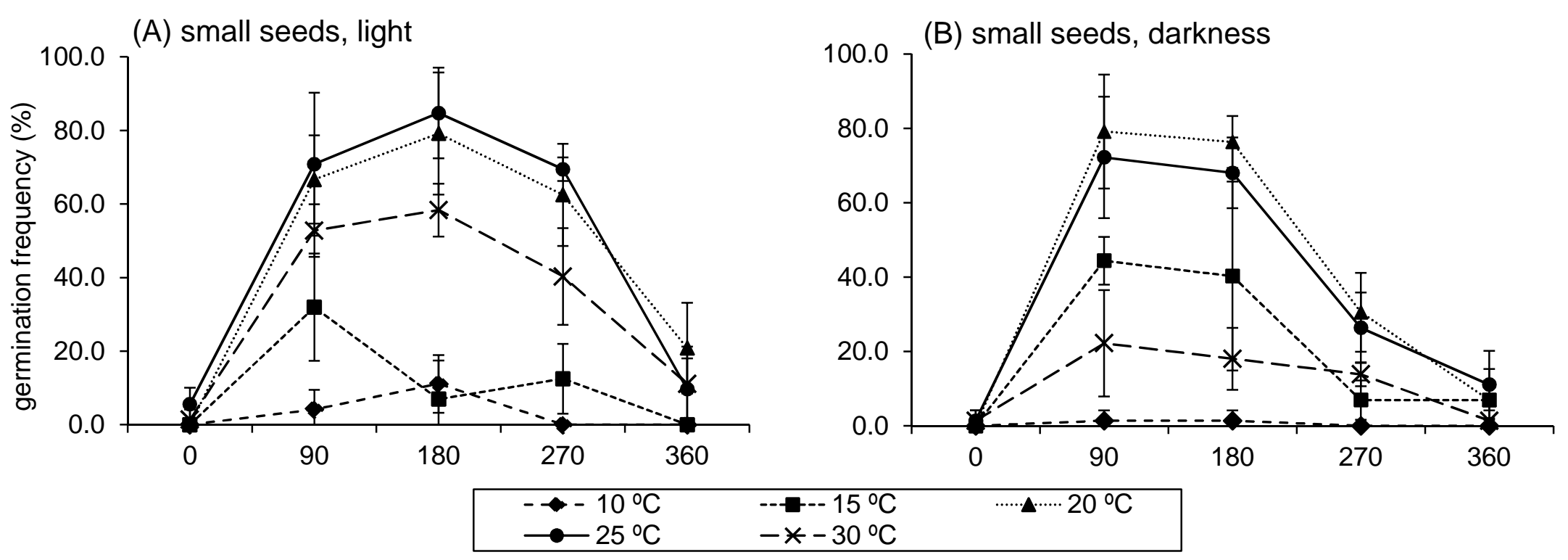

(C) large seeds, light

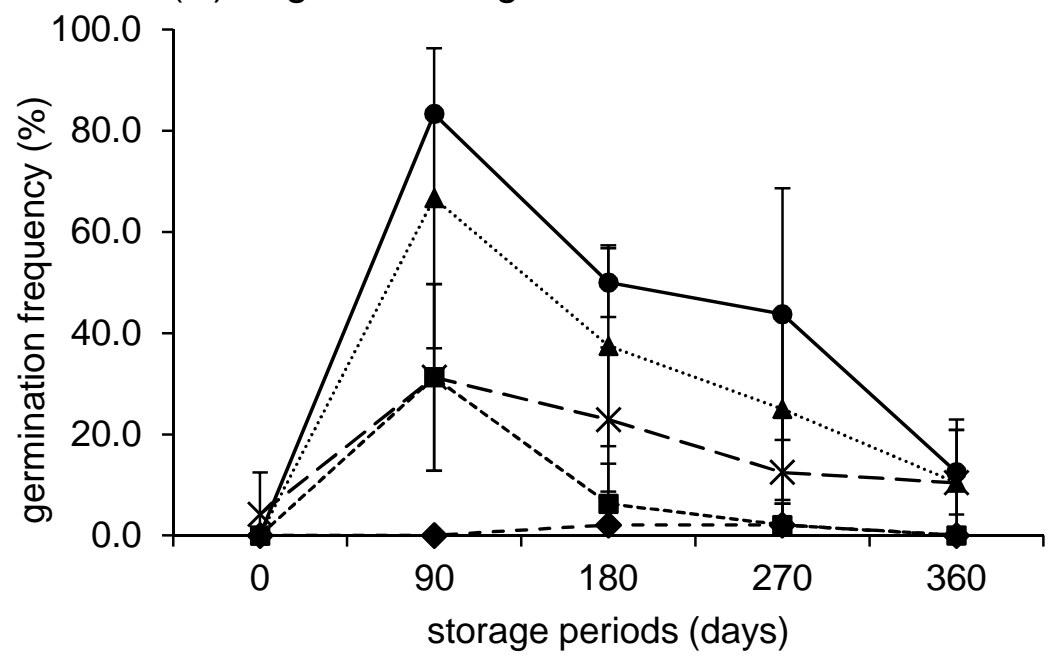

(D) large seeds, darkness

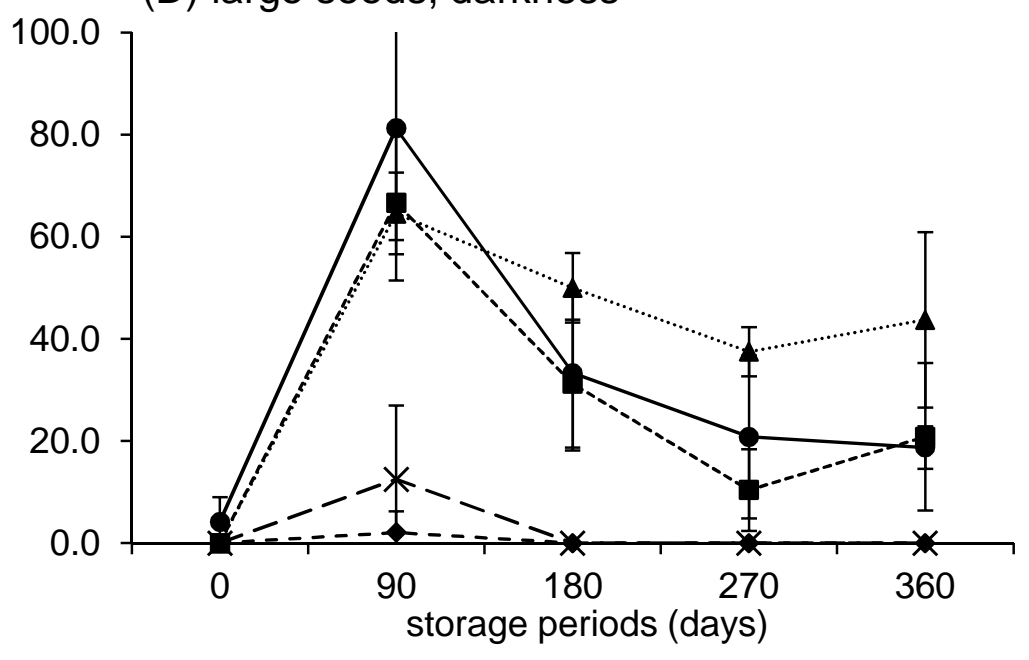


Table 1 Median germination time for $E$. ferox seeds, which is the days required for the germination frequency of all four replicates to reach at least $50 \%$ within the 60 -day experimental period.

\begin{tabular}{|c|c|c|c|c|}
\hline \multirow{3}{*}{$\begin{array}{l}\text { Germination } \\
\text { temperature }\end{array}$} & \multicolumn{4}{|c|}{ Storage periods } \\
\hline & \multicolumn{2}{|c|}{90 days } & \multirow{2}{*}{$\frac{180 \text { days }}{\text { small seeds }}$} & \multirow{2}{*}{$\begin{array}{c}270 \text { days } \\
\text { small seeds }\end{array}$} \\
\hline & small seeds & large seeds & & \\
\hline $20^{\circ} \mathrm{C}$ & $20.8 \pm 9.5$ & - & $11.5 \pm 6.1$ & - \\
\hline $25^{\circ} \mathrm{C}$ & $10.8 \pm 2.6$ & $8.5 \pm 1.5$ & $5.5 \pm 0.5$ & $14.5 \pm 1.7$ \\
\hline $30^{\circ} \mathrm{C}$ & - & - & $8.0 \pm 1.6$ & - \\
\hline
\end{tabular}


Table 2 Effects of germination temperature, light condition, and seed size on germination of $E$. ferox seeds

\begin{tabular}{lcccc}
\hline & Estimate & SE & $Z$-value & $P$ \\
\hline Germination temperature & -0.12 & 0.02 & -5.087 & $<0.001$ \\
Light condition (in light) & -2.83 & 0.56 & -5.081 & $<0.001$ \\
Seed size (small) & -1.17 & 0.57 & -2.048 & 0.04 \\
Germination temperature $\times$ Light condition (in light) & 0.12 & 0.02 & $5.19<0.001$ \\
Germination temperature $\times$ Seed size (small) & 0.05 & 0.02 & 2.14 & 0.03 \\
Intercept & 2.86 & 0.54 & 5.29 & $<0.001$ \\
\hline Al
\end{tabular}

AIC (selected model/null model) : 437.9/441.1

Models that have the highest power of explanation are shown. 